\title{
Fitness of Escherichia coli strains carrying expressed and partially silent IncN and IncP1 plasmids
}

\author{
Bruce Humphrey ${ }^{1}$, Nicholas R Thomson², Christopher M Thomas ${ }^{3}$, Karen Brooks², Mandy Sanders², Anne A Delsol ${ }^{4}$, \\ John M Roe ${ }^{4}$, Peter M Bennett ${ }^{1}$ and Virve I Enne ${ }^{1,5^{*}}$
}

\begin{abstract}
Background: Understanding the survival of resistance plasmids in the absence of selective pressure for the antibiotic resistance genes they carry is important for assessing the value of interventions to combat resistant bacteria. Here, several poorly explored questions regarding the fitness impact of IncP1 and IncN broad host range plasmids on their bacterial hosts are examined; namely, whether related plasmids have similar fitness impacts, whether this varies according to host genetic background, and what effect antimicrobial resistance gene silencing has on fitness.
\end{abstract}

Results: For the IncP1 group pairwise in vitro growth competition demonstrated that the fitness cost of plasmid RP1 depends on the host strain. For the IncN group, plasmids R46 and N3 whose sequence is presented for the first time conferred remarkably different fitness costs despite sharing closely related backbone structures, implicating the accessory genes in fitness. Silencing of antimicrobial resistance genes was found to be beneficial for host fitness with RP1 but not for IncN plasmid pVE46.

Conclusions: These findings suggest that the fitness impact of a given plasmid on its host cannot be inferred from results obtained with other host-plasmid combinations, even if these are closely related.

\section{Background}

Antibiotic resistance is a serious threat to human and animal health and new ways to combat it are urgently needed. Broad-host range plasmids, such as those belonging to the IncN and IncP1 groups are important to the dissemination of antibiotic resistance due to their ability to replicate in a variety clinically relevant bacterial species and environments [1,2]. Indeed, both IncN and IncP1 group plasmids have been shown to encode clinically important resistance determinants such as $b l a_{\mathrm{CTX}-\mathrm{M}}, b l a_{\mathrm{IMP}}, b l a_{\mathrm{NDM}}, b l a_{\mathrm{VIM}}$ and $q u r$ [3-8], whilst IncN plasmids have also been strongly implicated in the recent spread of $b l a_{\text {KPC }}$ encoded carbapenemases [9].

Antimicrobial resistance can sometimes be accompanied by a reduction in biological fitness in the absence

\footnotetext{
* Correspondence: v.i.enne@qmul.ac.uk

${ }^{1}$ Bristol Centre for Antimicrobial Research, Department of Cellular and Molecular Medicine, University of Bristol, Medical Sciences Building, University Walk, Bristol, BS8 1TD, UK

Full list of author information is available at the end of the article
}

of antibiotic selection. Hence, less fit resistant bacteria may be outcompeted and displaced by fitter, susceptible bacteria in the absence of antibiotic use, leading to the suggestion that it may be possible to reduce the prevalence of antibiotic resistance by temporarily restricting prescribing. In practice, however, such approaches have enjoyed mixed success [10-14].

A fitness cost of antibiotic resistance has often been demonstrated in the case of chromosomal mutations conferring resistance, for example in the case of fus $A$ mutations conferring resistance to fusidic acid [15] and gyrA mutations conferring resistance to fluoroquinolones [16]. However, compensatory mutations can arise at secondary sites that reduce or eliminate this cost [17]. In the case of acquired antibiotic resistance genes encoded on mobile genetic elements such as plasmids and transposons, the existence of a fitness cost is less clear. While early studies which often investigated cloning plasmids and/or laboratory strains demonstrated a cost to plasmid carriage [18-21], some more recent data

\section{Biomed Central}


using naturally-occurring plasmids and/or wild-type bacteria have failed to demonstrate significant costs and have sometimes shown a benefit. For example, the small sulphonamide and streptomycin resistance plasmid p9123 confers a 4\% per generation fitness benefit in $E$. coli [22], and a benefit has also been demonstrated for some apramycin resistance plasmids isolated from bovine E. coli [23]. A number of antibiotic resistance encoding plasmids and transposons conferred only a low fitness cost or were cost-neutral in the wild-type $E$. coli strain 345-2RifC in vitro and in the pig gut [24], whilst the resistance plasmid R751 and variants of it enhanced fitness under some growth conditions in $E$. coli [25]. It is likely that the fitness cost a particular plasmid exerts on its host is variable depending on the plasmid as well as on the host itself. However, few studies have examined the fitness cost of a single plasmid on different strains of bacteria. The genetic factors, be they plasmid or host-encoded, that influence fitness are poorly understood, and it is not known whether related plasmids influence fitness in similar ways.

There are theoretically three ways in which a bacterial host can counteract the potential fitness cost exerted by antibiotic resistance genes carried on mobile genetic elements; the first is to acquire compensatory mutations, while the second is outright loss of the mobile genetic element. A third possibility is that bacteria could switch off the expression of resistance genes when they are not required whilst retaining the genes themselves in order to lower costs. We have previously demonstrated silencing of antibiotic resistance genes carried on the broad-host range plasmids pVE46 and RP1 by the wild-type E. coli strain 345-2RifC [26]. Following passage through the pig gut, a small proportion ( $0.5 \%)$ of $345-2 \mathrm{RifC}(\mathrm{pVE} 46)$ colonies recovered lost expression of one or more of the four resistance genes encoded on the plasmid. Such isolates had retained the pVE46 plasmid and in most cases, intact, wild-type resistance genes and promoters were present, but no resistance gene mRNA was expressed. Similar results were found for three colonies of 345-2RifC(RP1) that also lost resistance following passage through the pig gut. Antibiotic resistance gene silencing appears to be restricted to only the plasmid with minimal effect on the remainder of the genome and is thought to be due to a mutation on the chromosome of E. coli 345-2RifC [26]. Its precise mechanism is yet to be elucidated.

Here, we examine several unexplored questions regarding the fitness impact of broad host range IncP and IncN plasmids on their hosts; namely, the effect of the host background on fitness, whether related plasmids have similar fitness impacts and the fitness impact of antimicrobial resistance gene. To facilitate this task we also report the complete nucleotide sequence of the IncN plasmid N3.

\section{Results and discussion}

The effect of host background on plasmid fitness impact

The effect of host genetic background on the fitness impact of plasmid RP1 in the laboratory was investigated (Table 1). Five unrelated host strains representing all four E. coli phylogenetic groups were studied; E. coli 345-2RifC (group B1) and 343-9 (group D) of porcine origin, 99-24 (group D) and 99-40 (group B2) of human clinical origin (urine) and K12 (group A) JM109, a laboratory strain. Phylogenetic group B2, and to a lesser extent phylogenetic group D tend to be associated with extra-intestinal infections, whereas strains belonging to groups A and B1 are often commensals [27]. There was considerable variation in the results obtained from different host backgrounds. The fitness impacts of RP1 on the strains of animal origin (343-9 and 345-8) were significantly lower than the costs imposed on those of human origin (JM109, 99-24 and 99-40) $(p<0.002$ in all cases).

These results suggest that the fitness impact a particular antibiotic resistance plasmid confers on a given bacterial species is dependent on the genotype of the specific host strain that it is in. This conclusion is perhaps intuitive, but has to the best of our knowledge not been demonstrated for antibiotic resistance-encoding plasmids. One might expect this to be the case based on previous work by Dahlberg and Chao, who showed that amelioration of fitness costs conferred by the plasmids R1 and RP4 (very similar to plasmid RP1 used here) on E. coli K12 J53 depended on genetic changes in the host chromosome, thus implying a host genome component is involved in determining plasmid-encoded fitness cost [19]. Similarly, the fitness cost and stability of the plasmid pB10 was highly variable in strains of different species [28,29]. Previous studies have also shown that target mutations leading to antibiotic resistance, for example gyrA mutations in Campylobacter jejuni or $23 \mathrm{~S}$ rRNA mutations leading to clarithromycin resistance in Helicobacter pylori have different fitness effects in different host backgrounds [30,31]. It is not currently known which host genetic components may be important for determining the effect a plasmid will have on host fitness and it is likely that these will vary depending on

Table 1 In vitro fitness impact of plasmid RP1 on different $E$. coli host strains

\begin{tabular}{ll}
\hline E. coli Host Strain & Fitness impact per generation (\%) \\
\hline $345-2$ RifC & $-3.3 \pm 0.9$ \\
\hline $343-9$ & $+0.8 \pm 0.9$ \\
\hline $99-24$ & $-9.1 \pm 4.2$ \\
\hline $99-40$ & $-9.7 \pm 1.4$ \\
\hline K12 JM109 & $-5.8 \pm 1.0$ \\
\hline
\end{tabular}


the host-plasmid combination concerned. This finding has important implications for anyone wishing to use fitness cost as a parameter to model the spread or decline of a given plasmid in a bacterial population, perhaps in response to changes in antimicrobial selection, as it highlights the need to determine fitness in several different host genetic backgrounds. Similarly, recent work has also shown that fitness cost of antimicrobial resistance is variable depending on the growth conditions used in laboratory measurements [25,32], re-iterating the need for multiple measurements to obtain accurate fitness cost estimates.

\section{DNA sequence analysis of N3}

Despite being a well-studied archetypal plasmid isolated in the 1960s, the DNA sequence of the IncN plasmid N3 has not previously been reported [33]. Sequence analysis revealed that it is $54205 \mathrm{bp}$ in length, has a GC content of $51.1 \%$ and encodes 62 putative open reading frames (Table 2). It shares a common backbone with other IncN plasmids such as R46 [34] and the recently described multiple antibiotic resistance plasmid pKOX105 [3] (Figure 1). The shared region comprises the plasmid's replication and transfer functions as well as genes encoding stable inheritance, anti-restriction and UV protection functions. N3 also encodes a class 1 integron and, in common with pKOX105 but lacking from R46, a type 1 restriction modification system. This characteristic and the high sequence identity shown between a number of proteins encoded by the two plasmids suggests pKOX105 may have evolved from a N3-like ancestor. N3 also encodes a unique region absent from other known IncN plasmids, bordered by IS26 elements. This comprises the tet $(\mathrm{A})$ genes for tetracycline resistance, a putative bacA-like bacitracin resistance gene and seven novel genes. Several of the novel genes are predicted to have metabolic functions, most likely amino acid metabolism. Outside this region, the high similarity between $\mathrm{N} 3$ and other antibiotic resistance encoding IncN plasmids suggests that they have evolved from a common ancestor and diverged from each other relatively recently. The resistance region appears to have originated as a single class 1 integron initially carrying only an aadA1 cassette which has subsequently acquired further cassettes and/or insertions.

\section{The effect of the genetic composition of the plasmid on its fitness impact}

The fitness impacts of the related plasmids RP1 and pUB307 and R46 and N3 on E. coli 345-2RifC were compared. pUB307 is a derivative of RP1 which has lost the $\operatorname{Tn} 1$ transposon. The fitness impact of the $\operatorname{Tn} 1$ transposon itself has been demonstrated to be variable depending on the insertion site, with some insertion sites conferring a fitness benefit [24]. Here, pUB307 had a small fitness cost of $1.9 \pm 0.8 \%$ per generation, significantly lower than that of RP1 of $-3.3 \pm 0.9 \%$ per generation (students t-test $p=0.041$ ). In animals, carriage of neither RPI nor pUB307 influenced the ability of $E$. coli $345-2$ RifC to colonize the pig gut compared to the plasmid-free 345-2RifC (ANOVA F value $=0.77, p=0.471$ ).

R46 was previously determined to confer a fitness cost of $-3.3 \pm 1.7 \%$ per generation [24] in the laboratory, whilst no significant fitness cost in pigs was detected. In contrast, here, N3 was demonstrated to have a significantly higher fitness cost in the laboratory of $9.1 \pm 1.8 \%$ per generation (students t-test $p=0.0002$ ). In animals, $345-2 \mathrm{RifC} / \mathrm{N} 3$ colonised the pig gut significantly worse than the plasmid free strain or 345-2RifC/R46 (ANOVA $\mathrm{F}$ value $=3.41, p=0.035$ )

In the case of RP1 versus pUB307, these results suggest that the lower fitness cost of pUB307 compared to RP1 is related to the presence of less DNA. It is known that in single copy the $\operatorname{Tn} 1$ transposon does not itself have a detrimental effect on host fitness and can occasionally confer a benefit depending on the insertion site [24]. Therefore, it can be assumed that in this case the advantage gained by deletion of $\operatorname{Tn} 1$ is due to the presence of less DNA and a lowered burden of gene expression as the TEM beta-lactamase encoded by the transposon is normally expressed at high levels. As RP1 is present in multiple copies, the burden of gene expression will be higher on the plasmid than in the case of Tn1 insertion at a single chromosomal site. Possible additional epistatic fitness effects due to the insertion site of Tn1 in RP1 will also be absent in pUB307.

The reason(s) why N3 and R46 have markedly different fitness costs is less clear, as the two plasmids are a similar size and share the same replication and conjugation functions. The marked fitness difference is therefore most likely due to accessory genes. The antibiotic resistance gene complement of the two plasmids is similar, although not identical (Figure 1, Table 2). The main differences are the presence of the arsCBADR on $\mathrm{R} 46$ and a Type 1 restriction system and a number of putative metabolic genes on N3. It is likely that one or more additional genes on N3 are responsible for the high fitness cost of N3 but this hypothesis requires experimental confirmation. Alternatively, a small mutation in the core plasmid genome may also be responsible.

\section{The fitness impact of plasmids carrying silent antibiotic resistance genes}

... In addition to variable fitness costs brought about by different host-plasmid combinations, bacteria may influence the cost of plasmid carriage by modulation of gene expression. As antibiotic resistance can impose a fitness cost on the bacterial host in the absence of antibiotic 
Table 2 Positions and putative functions of open reading frames identified in plasmid N3

\begin{tabular}{|c|c|c|c|c|}
\hline $\begin{array}{l}\text { Gene/ } \\
\text { orf }\end{array}$ & Position & Putative Function & Closest match (Accession) ${ }^{1}$ & $\begin{array}{l}\text { Protein identity } \\
(\%)\end{array}$ \\
\hline repA & $3-722$ & Initiation of plasmid replication & pKOX105 (ADH29527) & 100 \\
\hline$\overline{\operatorname{ardK}}$ & $1282-1623$ & Regulation of ccg genes & pEC_L46 (ADL14210) & 100 \\
\hline$m p r$ & $1638-2429$ & Zinc metalloproteinase & pLEW517 (YP_001096387) & 100 \\
\hline mucB & $2580-3845$ & UV protection & pKOX105 & 100 \\
\hline mucA & $3833-4273$ & UV protection & pEC_L46 & 100 \\
\hline $\operatorname{ard} B$ & $4688-5113$ & Type I antirestriction system & R46 (NP_511215) & 99 \\
\hline $\operatorname{ardR}$ & $5171-5575$ & Regulator of CUP controlled ccgEll regulon & pEC_L46 & 100 \\
\hline ccgEIII & $5585-5824$ & Unknown & R46 & 100 \\
\hline $\operatorname{ccg} A l$ & $7332-7511$ & Regulation of ccgAll expression & R46 & 100 \\
\hline ccgAll & 7566-7886 & Prevention of RecA overproduction & pKOX105 & 100 \\
\hline pN3_011 & $7997-8341$ & Unknown & R46 & 100 \\
\hline$s t b C$ & $8523-8891$ & Stable plasmid inheritance & R46 & 100 \\
\hline$s t b B$ & 8893-9609 & Stable plasmid inheritance & pKOX105 & 100 \\
\hline$s t b A$ & 9618-10037 & Stable plasmid inheritance & pKOX105 & 100 \\
\hline trak & 10528-10944 & Conjugal transfer protein & pKOX105 & 100 \\
\hline traj & 10946-12475 & Conjugal transfer protein & pKP96 (YP_002332894) & 100 \\
\hline tral & $12475-15717$ & Conjugal nickase and helicase & pKP96 & 100 \\
\hline fipA & $15717-16343$ & Fertility inhibition of IncP plasmids & pKM101 (AAC63100) & 100 \\
\hline nuc & $16517-17050$ & Endonuclease & pKOX105 & 100 \\
\hline traG & 17050-18045 & Conjugal transfer protein & pKOX105 & 100 \\
\hline traF & $18087-19247$ & Conjugal transfer protein & pKOX105 & 100 \\
\hline $\operatorname{traO}$ & $19247-20131$ & Conjugal transfer protein & pEC_L46 & 100 \\
\hline traE & $20142-20840$ & Conjugal transfer protein & pEC_L46 & 100 \\
\hline $\operatorname{traN}$ & 20830-20967 & Conjugal transfer protein & pEC_L46 & 100 \\
\hline $\operatorname{traD}$ & $21059-22099$ & Conjugal transfer protein & pEC_L46 & 100 \\
\hline eex & $22115-22342$ & Entry exclusion & pKOX105 & 100 \\
\hline traC & $22350-23063$ & Conjugal transfer protein & pKOX105 & 100 \\
\hline $\operatorname{traB}$ & $23081-25681$ & Conjugal transfer protein & pKOX105 & 100 \\
\hline $\operatorname{traA}$ & $25681-25998$ & Conjugal transfer protein & pKOX105 & 100 \\
\hline $\operatorname{traM}$ & $26048-26341$ & Conjugal transfer protein & pKOX105 & 100 \\
\hline korA & $26351-26632$ & Unknown & R46 & 100 \\
\hline tral & $26641-27375$ & Conjugal transfer protein & pKOX105 & 100 \\
\hline korB & $27484-27789$ & DNA binding protein & pKOX105 & 99 \\
\hline pN3_034 & 27805-28149 & Unknown & pKOX105 & 100 \\
\hline kikA & $28146-28460$ & Killer protein of TrbM family & pKOX105 & 100 \\
\hline pN3_036 & 28496-28807 & Unknown & R46 & 100 \\
\hline$m r r$ & $28863-29504$ & Restriction endonuclease & pKOX105 & 100 \\
\hline pN3_038 & 29509-29715 & Unknown & pKP96 & 100 \\
\hline $\begin{array}{l}\text { EcoRll } \\
\text { met }\end{array}$ & $30055-31530$ & Modification methylase & pKOX105 & 100 \\
\hline ECORII & $31564-32778$ & Type-2 restriction enzyme & pKOX105 & 100 \\
\hline tnpA & $33039-33833$ & IS6100 transposase & pEK499 (YP_003108355) & 100 \\
\hline pN3_042 & 33999-34724 & Unknown & pAPEC-O1-R (YP_001481449) & 100 \\
\hline sul1 & $34938-35777$ & Sulphonamide resistant dihydropteroate synthase & R46 & 100 \\
\hline qacE $\triangle 1$ & $35771-36118$ & $\begin{array}{l}\text { Quaternary ammonium compound resistance, } \\
\text { truncated }\end{array}$ & R46 & 100 \\
\hline
\end{tabular}


Table 2 Positions and putative functions of open reading frames identified in plasmid N3 (Continued)

\begin{tabular}{|c|c|c|c|c|}
\hline aadA2 & $36282-37073$ & Aminoglycoside adenyltransferase & p1206 (ACC77487) & 100 \\
\hline int/1 & 37219-38232 & Class 1 integrase & pKOX105 & 100 \\
\hline uvpl & 38625-39194 & Site specific recombinase & pKOX105 & 100 \\
\hline $\operatorname{tnp} A$ & $39506-40210$ & IS26 transposase & pKOX105 & 100 \\
\hline pN3_049 & $40247-40750$ & Putative shikimate dehydrogenase (repeat protein) & Pantotea sp. (YP_004116848) & 59 \\
\hline $\operatorname{tet}(\mathrm{A})$ & $41265-42464$ & Tetracycline efflux protein & pQKp331H (ABS19074) & 100 \\
\hline tetR & $42592-43233$ & Repressor protein for Tet(A) & pQKp331H & 100 \\
\hline pN3_052 & $43438-43941$ & Unknown & No good match & \\
\hline pN3_053 & $44147-44563$ & Unknown & pLVPK (NP_943518) & 59 \\
\hline tnp orfA & $44921-45265$ & IS911 transposase, truncated & Shigella flexneri 2a str. 2457 T (NP_835957) & 80 \\
\hline pN3_055 & $45468-46295$ & Putative bacitracin resistance protein & Acinetobacter sp. DR1 (YP_003733303) & 62 \\
\hline pN3_056 & $46450-47589$ & Putative amino acid racemase & $\begin{array}{l}\text { Pectobacterium carotovorum PC1 } \\
\text { (YP_003017826) }\end{array}$ & 73 \\
\hline pN3_057 & $47686-48597$ & Putative LysR-type regulator & $\begin{array}{l}\text { Shewanella halifaxensis HAW-EB4 } \\
\text { (YP_001674862) }\end{array}$ & 56 \\
\hline pN3_058 & 48594-49526 & $\begin{array}{l}\text { Putative amino acid dehydrogenase/ } \\
\text { cyclodeaminase }\end{array}$ & $\begin{array}{l}\text { Pectobacterium carotovorum subsp. } \\
\text { brasiliensis PBR1692 } \\
\text { (ZP_03825565) }\end{array}$ & 72 \\
\hline pN3_059 & $50018-50623$ & Putative sodium:dicarboxylate symporter & Burkholderia dolosa AUO158 (ZP_04944635) & 56 \\
\hline tnpA & $50681-51385$ & IS26 transposase & pKOX105 & 100 \\
\hline$h s d M$ & $51636-53192$ & Type I restriction enzyme Ecoprrl M protein & Escherichia coli B185 (ZP_06660389) & 90 \\
\hline pN3_062 & $53656-54165$ & Unknown & pKOX105 & 90 \\
\hline
\end{tabular}

${ }^{1}$ Where more than one protein shares the exact same identity with pN3 an example is given

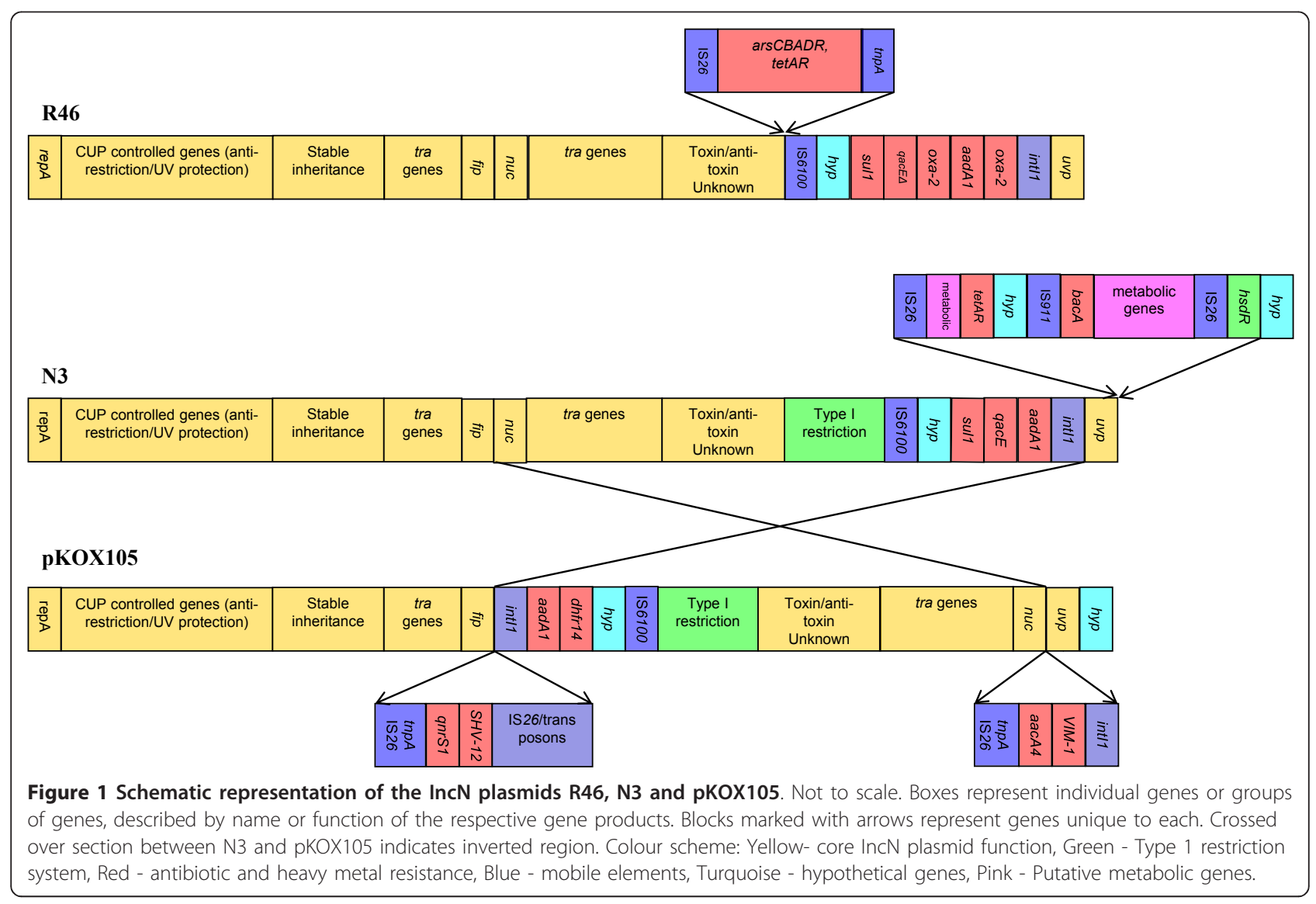


Table 3 Characteristics of bacterial strains and plasmids used in this study

\begin{tabular}{|c|c|c|c|c|}
\hline Plasmids & Resistance Profile $^{1}$ & Resistance Genotype & Inc Group & Reference or source \\
\hline pVE46 & AMP, STR, SUL, TET & bla $_{\mathrm{OXA}-2}$, sul1, a adA1, tet(A) & $\mathrm{N}$ & [26] \\
\hline R46 & AMP, STR, SUL, TET & bla $_{\mathrm{OXA}-2} \times 2$, sull, aadA1, tet( $(\mathrm{A})$ & $\mathrm{N}$ & [34] \\
\hline RP1 & AMP, KAN, TET & bla $a_{\mathrm{TEM}-2}, \operatorname{aphA}, \operatorname{tet}(\mathrm{A})$ & $P$ & {$[35]$} \\
\hline PUB307 & KAN, TET & $a p h A, \operatorname{tet}(\mathrm{A})$ & $P$ & {$[36]$} \\
\hline N3 & STR, SUL, TET & sul1, aadA1, tet( $(A)$ & $\mathrm{N}$ & [33] \\
\hline Bacterial Strains & & & Phylogenetic Group & \\
\hline 345-2RifC & RIF & RpoB H526Y & B1 & [24] \\
\hline $343-9$ & & NA & $\mathrm{D}$ & [24] \\
\hline $99-24$ & & NA & D & [11] \\
\hline $99-40$ & & NA & B2 & [11] \\
\hline K12 JM109 & NAL & NA & A & Promega, Southampton, UK \\
\hline $\mathrm{L}^{2}$ & RIF & bla ${ }_{\mathrm{OXA}-2}$, sul1, aadA1, $\operatorname{tet}(\mathrm{A})$ & B1 & {$[26]$} \\
\hline$L 4^{2}$ & RIF, TET & bla $a_{\mathrm{OXA}-2}$, sull, aadAl, tet(A) & B1 & [26] \\
\hline$\overline{\mathrm{L}^{2}}$ & AMP, RIF, SUL & bla oxA-2, sul1, aadA1 $_{1}$ & B1 & [26] \\
\hline$\overline{P 1^{3}}$ & KAN, RIF & bla $a_{\mathrm{TEM}-2}$ & B1 & {$[26]$} \\
\hline$\overline{P 2^{3}}$ & $\mathrm{RIF}$ & bla $a_{\mathrm{TEM}-2}, a p h A, \operatorname{tet}(\mathrm{A})$ & B1 & {$[26]$} \\
\hline
\end{tabular}

${ }^{1}$ AMP, ampicillin; KAN, kanamycin; NAL, nalidixic acid; RIF, rifampicin; STR, streptomycin; SUL, sulfamethoxazole; TET, tetracycline; NA, not applicable

2345-2RifC strain with pVE46 encoding silent antimicrobial resistance genes

3345-2RifC strain with RP1 encoding silent antimicrobial resistance genes

selection, one might expect phenotypic silencing of plasmid-borne antibiotic resistance genes to confer a fitness advantage. The fitness costs of the plasmids pVE46 and RP1 on E. coli 345-2RifC had previously been established as moderate in vitro and non-detectable in vivo. Neither plasmid had a detectable cost in the pig gut [26]. However, in both cases isolates that no longer expressed the resistance genes encoded on them but retained intact and wild-type resistance genes, were recovered during the pig gut colonisation experiments [26]. Here, we investigated whether silencing of antibiotic resistance genes carried on pVE46 and RP1 had an effect on their fitness impact.

Three isolates with silent pVE46-encoded antibiotic resistance genes were investigated in vitro; L4, L5 and L7 (Table 3). Each isolate demonstrated variable degrees of antibiotic resistance gene silencing [26]. Pair-wise growth competition assays were performed between silent isolates and the wild-type isolates expressing all antibiotic resistance genes. Isolate L5 had a slight in vitro cost of $-2.1 \% \pm 1.7 \%$ per generation whilst isolates L4 and L7 had slight fitness advantages of $+1.1 \pm 1.4 \%$ and $+1.2 \% \pm 0.5 \%$ per generation, respectively. However, the statistical significance of these results was low and overall the impact of silencing of pVE46 genes on fitness appeared negligible. The in vivo ability of isolate L5 to colonize the pig gut was found to be comparable to that of 345-2RifC(pVE46) (Figure 2).

In contrast, antibiotic resistance gene silencing had a significant effect on the fitness of E. coli 345-2RifC
(RP1). The silent isolates P1 and P2 (Table 3) both had fitness advantages of $+2.5 \pm 0.5 \%$ and $+4.1 \pm 3.7 \%$ in vitro, respectively. $\mathrm{P} 2$ was also able to colonize the pig gut better than 345-2RifC(RP1) (Figure 2).

Surprisingly, antibiotic resistance gene silencing did not confer a fitness advantage on isolates carrying the pVE46 plasmid, in vivo or in vitro. This suggests that in this case antibiotic resistance gene silencing may have

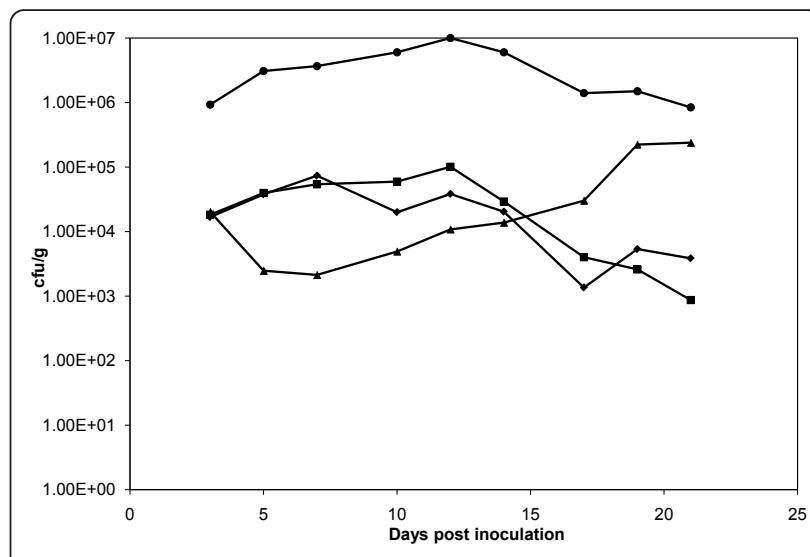

Figure 2 Recovery of $E$. coli 345-2RifC(pVE46) (squares), E. coli L5 (diamonds), E. coli 345-2RifC(RP1) (triangles) and E. coli P2 (circles) from pig faeces following oral inoculation of six animals. There was statistically no difference in recovery levels between 345-2RifC(pVE46) and L5 (ANOVA 0.5628, $p=0.4546$ ). However, P2 was recovered significantly more frequently than 3452RifC(RP1) (ANOVA 15.3169, $p=0.0002$ ). 
occurred by random chance that was fortuitously detected, or that if it exists, any fitness advantage only manifests itself under conditions not measured by our current assays. This observation may be explained by the fact that the initial cost conferred by carriage of pVE46 on E. coli $345-2$ RifC was moderate, $2.8 \pm 0.9 \%$, per generation. However, previous studies did show that pVE46-encoded antibiotic resistance genes were able to revert back to resistance at rates varying between $10^{-6}$ and $10^{-10}$ in vitro [26] suggesting that such strains may still pose a clinical threat.

In contrast, silencing of antibiotic resistance genes encoded on the plasmid RP1 conferred a significant fitness benefit both in vivo and in vitro. Such a strategy could be deemed beneficial for the bacterium, particularly if they were able to revert to antibiotic resistance again when challenged with antibiotic. However, this was not the case as none of the isolates with silent RP1 antibiotic resistance genes (P1, P2 or P3) were able to revert back to resistance in the laboratory. This suggests that the genetic event responsible for antibiotic resistance gene silencing of RP1 is not readily reversible, for example a transposon insertion or DNA deletion. Under such conditions one would expect the silenced DNA to eventually be lost, but until then it may act as an environmental reservoir of resistance genes.

In theory any fitness effects observed in silent isolates could also be attributed to unrelated mutations that may have arisen in the pig gut prior to their isolation. However, the silent isolate L5 is not known to carry any mutations compared to the wild-type 345-2RifC(pVE46) strain, whilst the possible role of unrelated mutations in the remaining isolates is yet to be determined (B.H. V.I. $E$ and N.R.T, unpublished data).

\section{Conclusions}

Overall, the results presented here show that the fitness balance between the host genotype and a given resistance plasmid is extremely delicate and that even minor differences in the host or in the plasmid can have substantial effects on fitness. Future studies on the subject should therefore investigate multiple hosts in order to draw any general conclusions about a particular plasmid. Without better molecular understanding of the processes involved, it is difficult to predict the fitness impact of a given host-plasmid association, and hence difficult to make predictions about the spread or decline of associated antibiotic resistance phenotypes. It is therefore important to study molecular host-plasmid interactions. In the absence of such data one should preferably use a range of host strains and plasmids when studying the fitness of a particular resistance phenotype. As plasmids belonging to the IncN and IncP1 groups are broad-host range and conjugative they will likely move from host to host until they encounter one where costs are negligible and subsequently go on to thrive with that host. Thus, such plasmids may be of particular concern in the dissemination of novel antibiotic resistance phenotypes.

In addition, bacteria can sometimes "hide" their resistance genotype by silencing it. This can create a fitness advantage for the bacteria, whereas in other cases the silent phenotype is reversible, indicating that there is a risk of treatment failure in anyone infected by bacteria with silent genes and being treated by one of the affected antibiotics.

Based on these observations, further work should now concentrate on understanding the molecular mechanisms responsible so that the underlying process are understood and used to help develop better treatment and prevention and control strategies.

\section{Methods}

\section{Bacterial strains and plasmids}

E. coli 345-2RifC, E. coli 345-8 and 343-9 are all commensal isolates of porcine origin. E. coli $345-2$ RifC is marked with a no-cost rifampicin-resistance mutation in RpoB (H526Y). Strains 99-24 and 99-40 are human urinary isolates, whilst E. coli K12 JM109 is a laboratory strain. Study strains were chosen on the basis that they did not carry acquired antibiotic resistance genes and that they exhibited good growth characteristics in laboratory media, with doubling ranging between 21 and 27 minutes in nutrient broth. Their phylogenetic group was determined as described previously [27]. The relatedness of the isolates was investigated by randomly amplified polymorphic DNA (RAPD) PCR [37].

The broad-host range plasmids RP1, pUB307, R46, pVE46 and N3 were introduced into host strains by conjugation using the agar mating method [26]. The 345-2RifC(pVE46) strain used was a variant passaged in the laboratory, the same from which silent isolates arose [26]. Derivatives of 345-2RifC(pVE46) and 345-2RifC (RP1), carrying silent antibiotic resistance genes were as described previously [26]. The characteristics of strains and plasmids used in this study are listed in Table 3.

\section{DNA sequencing and analysis}

DNA of IncN plasmid N3 was prepared by alkaline SDS maxiprep and $\mathrm{CsCl} / \mathrm{EtBr}$ density gradient centrifugation [38]. The E. coli N3 plasmid was sequenced to approximately 37 -fold shotgun sequence, totalling 1711 end sequences, from pUC19 (with insert sizes of 2-4 kb; 4-6 $\mathrm{kb}$ ) genomic shotgun libraries that were sequenced using big-dye terminator chemistry on ABI3730 automated sequencers. The assembly was generated using phrap2gap. All repeat regions and gaps were bridged by read-pairs or end-sequenced polymerase chain reaction 
(PCR) products again sequenced with big dye terminator chemistry on ABI3730 capillary sequencers. The sequence was manipulated to the 'Finished' standard [39].

\section{Competition experiments to assay in vitro fitness}

To assess the fitness impact of the plasmids upon E. coli host strains growth competition between plasmid-carrying and plasmid-free isogenic strain pairs was carried out as described previously in Davis minimal medium with $25 \mathrm{mg} / \mathrm{ml}$ glucose (DM25) [24]. To estimate bacterial counts, competition cultures were diluted as appropriate and spread in triplicate onto IsoSensitest agar (Oxoid) and onto IsoSensitest agar containing the relevant antibiotic. For the competition between the silent strains L5 or L7 and 345-2RifC(pVE46) the agar contained tetracycline at $25 \mu \mathrm{g} / \mathrm{ml}$, and for L4 it contained streptomycin at $25 \mu \mathrm{g} / \mathrm{ml}$. For competition between 345-2RifC(RP1) and P1 or P2 agar contained ampicillin at $25 \mu \mathrm{g} / \mathrm{ml}$. For competition between wildtype plasmids and their respective host strains it contained ampicillin for RP1 carrying strains, and tetracycline for the pUB307 and N3 carrying strains. Six replicates of each competition experiment were performed. Average per generation fitness (W) was calculated as $\mathrm{W}=1-\mathrm{b}$, where $\mathrm{b}$ is equal to $\mathrm{t}$ he gradient of the graph of $\ln$ (strain $x$ count/strain y count) per transfer, divided by the number of generations per transfer (T). $\mathrm{T}$ was calculated as $\ln$ (dilution factor) $/ \ln (2)$. The students t-test was used to estimate the statistical significance of results.

\section{Investigation of in vitro reversion to resistance}

The recovery of resistance by isolates with intact but silent RP1 encoded resistance genes was investigated by spreading undiluted and serially diluted overnight nutrient broth cultures onto IsoSensitest agar containing the appropriate antibiotic (ampicillin, $25 \mu \mathrm{g} / \mathrm{ml}$; kanamycin $30 \mu \mathrm{g} / \mathrm{ml}$; tetracycline, $25 \mu \mathrm{g} / \mathrm{ml}$ ). To calculate reversion frequencies, total cell counts were obtained following plating serial dilutions of the same culture onto antibiotic-free medium.

\section{Animal experiments}

Animal experiments were carried out using a modified method of that described previously [24]. For each experiment, six organic piglets from two litters of Saddleback-Duroc cross, weaned at five weeks of age, were housed as a single group for two weeks, to allow the animals to acclimatize to their surroundings. They were then randomly separated into two groups of three into pens with individual HEPA filtration and fed a standard organic feed (Organic feed company, grower/finisher pellets, UK) ad libitum. All procedures complied with the Animals (Scientific Procedures) Act 1986 and were performed under Home Office License.

Briefly, bacterial strains (E. coli 345-2RifC(pVE46), 345-2RifC(RP1), L5 and P1) were inoculated separately into six piglets as a single dose of $10^{10} \mathrm{cfu}$ per animal by oral gavage. Faecal samples were collected from each animal by digital manipulation on day 3, 5, 7, 10, 12, 14, 17, 19 and 21 post-inoculation and analysed within 24 hours. One gram of faeces was suspended in nine millilitres of saline and plated at appropriate dilutions onto six MacConkey agar plates containing $50 \mu \mathrm{g} / \mathrm{ml}$ rifampicin (detection limit $2 \mathrm{cfu} / \mathrm{g}$ ). They were incubated overnight at $37^{\circ} \mathrm{C}$ and colonies obtained replica plated onto MacConkey agar containing $50 \mu \mathrm{g} / \mathrm{ml}$ rifampicin with ampicillin $(25 \mu \mathrm{g} / \mathrm{ml})$, tetracycline $(25 \mu \mathrm{g} / \mathrm{ml})$, sulfamethoxazole $(500 \mu \mathrm{g} / \mathrm{ml})$ or streptomycin $(25 \mu \mathrm{g} / \mathrm{ml})$ for $\mathrm{L} 5$, and rifampicin with ampicillin, tetracycline or kanamycin $(30 \mu \mathrm{g} / \mathrm{ml})$ for $\mathrm{P} 1$, followed by replica plating onto MacConkey agar with rifampicin only.

\section{Nucleotide sequence accession number}

The N3 DNA sequence has been submitted to EMBL under the accession number FR850039.

\section{Acknowledgements}

This work was supported by grants OD2007 and OD2022 from the Department for Environment, Food and Rural Affairs (DEFRA) to P.M.B. and V. I.E, respectively, and grant 089222 awarded to V.I.E by the Wellcome Trust. We also thank The Wellcome Trust for their support of the Pathogen Genomics group under grant 076964.

\section{Author details}

${ }^{1}$ Bristol Centre for Antimicrobial Research, Department of Cellular and Molecular Medicine, University of Bristol, Medical Sciences Building, University Walk, Bristol, BS8 1TD, UK. ²Pathogen Genomics, Wellcome Trust Sanger Institute, Genome Campus, Hinxton, Cambridge, CB10 1SA, UK. ${ }^{3}$ School of Biosciences, University of Birmingham, Edgbaston, Birmingham, B15 2T, UK. ${ }^{4}$ Division of Animal Health and Husbandry, Department of Clinical Veterinary Science, University of Bristol, Langford, BS40 5DU, UK. ${ }^{5}$ Centre for Immunology and Infectious Disease, Blizard Institute, Barts and The London School of Medicine and Dentistry, 4 Newark Street, London, E1 2AT, UK.

\section{Authors' contributions}

$\mathrm{BH}, \mathrm{KB}, \mathrm{MS}, \mathrm{NRT}$ and VIE performed the experimental work and data analysis. AAD and PMB participated in the study design. NRT, CMT, JMR and VIE COordinated the study and participated in the design. BH, NRT, CMT and VIE drafted the manuscript. VIE and PMB conceived the study. All authors read and approved the final manuscript.

\section{Competing interests}

The authors declare that they have no competing interests.

Received: 17 September 2011 Accepted: 4 April 2012 Published: 4 April 2012

\section{References}

1. Suzuki H, Yano H, Brown CJ, Top EM: Predicting Plasmid Promiscuity Based on Genomic Signature. J Bact 2010, 192:6045-6055.

2. Toukdarian A: Plasmid strategies for broad-host-range replication in Gram-negative bacteria. In Plasmid Biology. Edited by: Funnell BE, Phillips GJ. Washington: ASM Press; 2004:259-270. 
3. Carattoli A, Aschbacher R, March A, Larcher C, Livermore DM, Woodford N: Complete nucleotide sequence of the IncN plasmid pKOX105 encoding VIM-1, QnrS1 and SHV-12 proteins in Enterobacteriaceae from Bolzano, Italy compared with IncN plasmids encoding KPC enzymes in the USA. $J$ Antimicrob Chemother 2010, 65:2070-2075.

4. Novais A, Canton R, Valverde A, Machado E, Galan JC, Peixe L, Carattoli A, Baquero $F$, Coque TM: Dissemination and persistence of $b l_{C T X-M-9}$ are linked to class 1 integrons containing CR1 associated with defective transposon derivatives from $\mathrm{Tn} 40$ located in early antibiotic resistance plasmids of IncHI2, IncP1-alpha and IncFI groups. Antimicrob Agents Chemother 2006, 50:2741-2750.

5. Poirel L, Bonnin RA, Nordmann P: Analysis of the Resistome of a Multidrug-Resistant NDM-1-Producing Escherichia coli Strain by HighThroughput Genome Sequencing. Antimicrob Agents Chemother 2011, 55:4224-4229

6. Psichogiou M, Tassios PT, Avlamis A, Stefanou I, Kosmidis C, Platsouka E Paniara O, Xanthaki A, Toutouza M, Daikos GL, Tzouvelekis LS: Ongoing epidemic of $b l_{\mathrm{VIM}-1}$ positive Klebsiella pneumonia in Athens, Greece: a prospective survey. J Antimicrob Chemother 2008, 61:59-63.

7. Shen $P$, Jiang $Y$, Zhou ZH, Zhang $J$, YU YS, Li L: Complete nucleotide sequence of pKP96, a 67850 bp multiresistance plasmid encoding qnrA1, aac (6')-Ib-c and $b l_{\mathrm{CTX}-\mathrm{M}-24}$ from Klebsiella pneumonia. J Antimicrob Chemother 2008, 62:1252-1256.

8. Xiong JH, Hynes MF, Ye HF, Chen HL, Yang YM, M'Zali F, Hawkey PM: bl IMP9 and its association with large plasmids carried by pseudomonas aeruginos isolates from the People's Republic of China. Antimicrob Agents Chemother 2006, 50:355-358.

9. Gootz TD, Lescoe MK, Dib-Hajj F, Dougherty BA, He W, Della-Latta P, Huard RC: Genetic Organization of Transposase Regions Surrounding bla (KPC) Carbapenemase Genes on Plasmids from Klebsiella Strains Isolated in a New York City Hospital. Antimicrob Agents Chemother 2009, 53:1998-2004.

10. Austin DJ, Kristinsson KG, Anderson RM: The relationship between the volume of antimicrobial consumption in human communities and the frequency of resistance. Proc Nat Acad Sci USA 1999, 96:1152-1156.

11. Enne VI, Livermore DM, Stephens P, Hall LMC: Persistence of sulphonamide resistance in Escherichia col in the UK despite national prescribing restriction. Lancet 2001, 357:1325-1328.

12. Gottesman B, Carmeli $Y$, Shitrit $P$, Chowers M: Impact of quinolone restriction on resistance patterns of Escherichia col isolated from urine by culture in a community setting. Clin Infect Dis 2009, 49:869-875.

13. Seppala H, Klaukka T, Vuopio-Varkila J, Muotiala A, Helenius H, Lager K, Huovinen P: Resistance TFSGfA: The effect of changes in the consumption of macrolide antibiotics on erythromycin resistance in group A streptococci in Finland. New Engl J Med 1997, 337:441-446.

14. Sundqvist M, Geli P, Andersson DI, Sjolund-Karlsson M, Runehagen A, Cars H, Abelson-Storby K, Cars O, Kahlmeter G: Little evidence for reversibility of trimethoprim resistance after a drastic reduction in trimethoprim use. J Antimicrob Chemother 2010, 65:350-360.

15. Nagaev I, Bjorkman J, Andersson DI, Hughes D: Biological cost and compensatory evolution in fusidic acid-resistant Staphylococcus aureus. Mol Microbiol 2001, 40:433-439.

16. Bjorkman J, Hughes D, Andersson Dl: Virulence of antibiotic-resistant Salmonella typhimuriu. Proc Nat Acad Sci USA 1998, 95:3949-3953.

17. Andersson Dl: The biological cost of mutational resistance: any practical conclusions? Curr Op Microbiol 2006, 9:461-465.

18. Bouma JE, Lenski RE: Evolution of a bacteria/plasmid association. Nature 1988, 335:351-352.

19. Dahlberg C, Chao L: Amelioration of the cost of conjugative plasmid carriage in Escherichia col K12. Genetics 2003, 165:1641-1649.

20. McDermott PJ, Gowland P, Gowland PC: Adaptation of Escherichia col growth rates to the presence of pBR322. Lett Appl Microbiol 1993, 17:139-143.

21. Valenzuela MS, Ikpeazu EV, Siddiqui KAl: E. coli growth inhibition by a high copy number derivative of plasmid pBR322. Biochem Biophys Rese Comm 1996, 219:876-883

22. Enne VI, Bennett PM, Livermore DM, Hall LMC: Enhancement of host fitness by the sul-coding plasmid p9123 in the absence of an evolutionary history between host and plasmid. J Antimicrob Chemother 2004, 53:958-963.
23. Yates CM, Shaw DJ, Roe AJ, Woolhouse MEJ, Amyes SGB: Enhancement of bacterial competitive fitness by apramycin resistance plasmids from non-pathogenic Escherichia col. Biol Lett 2006, 2:463-465.

24. Enne VI, Delsol AA, Davis GR, Hayward SL, Roe JM, Bennett PM: Assessment of the fitness impacts on Escherichia col of acquisition of antibiotic resistance genes encoded by different types of genetic element. $J$ Antimicrob Chemother 2005, 56:544-551.

25. Petersen A, Aarestrup FM, Olsen JE: The in vitr fitness cost of antimicrobial resistance in Escherichia col varies with the growth conditions. FEMS Microbiol Lett 2009, 299:53-59.

26. Enne VI, Delsol AA, Roe JM, Bennett PM: Evidence of antibiotic resistance gene silencing in Escherichia col. Antimicrob Agents Chemother 2006, 50:3003-3010.

27. Clermont $\mathrm{O}$, Bonacorsi S, Bingen E: Rapid and simple determination of the Escherichia col phylogenetic group. Appl Environ Microbiol 2000, 66:4555-4558

28. De Gelder L, Ponciano JM, Joyce P, Top EM: Stability of a promiscuous plasmid in different hosts: no guarantee for a long-term relationship. Microbiol-(UK) 2007, 153:452-463.

29. Heuer H, Fox RE, Top EM: Frequent conjugative transfer accelerates adaptation of a broad-host-range plasmid to an unfavorable Pseudomonas putida host. FEMS Microbiol Ecol 2007, 59:738-748.

30. Luo N, Pereira S, Sahin O, Lin J, Huang S, Michel L, Zhang Q: Enhanced in viv fitness of fluoroquinolone-resistant Campylobacter jejun in the absence of antibiotic selection pressure. Proc Nat Acad Sci USA 2005, 102:541-546.

31. Bjorkholm B, Sjolund M, Falk PG, Berg OG, Engstrand L, Andersson DI: Mutation frequency and biological cost of antibiotic resistance in Helicobacter pylor. Proc Nat Acad Sci USA 2001, 98:14607-14612.

32. Paulander W, Maisnier-Patin S, Andersson DI: The fitness cost of streptomycin resistance depends on rps mutation, carbon source and RpoS. Genetics 2009, 183:539-546.

33. Brown AMC, Coupland GM, Willetts NS: Characterization of IS4, an insertion sequence found on two IncN plasmids. J Bact 1984, 159:472-481.

34. Brown AMC, Willetts NS: A physical and genetic map of the IncN plasmid R46. Plasmid 1981, 5:188-201.

35. Pansegrau W, Lanka E, BP T, Figurski DH, Guiney DG, Haas D, Helinski DR, Schwab H, Stanisich VA, Thomas CM: Complete nucleotide sequence of Birmingham IncP alpha plasmids. Compilation and comparative analysis. J Mol Biol 1994, 239:623-663.

36. Bennett PM, Grinstead J, Richmond MH: Transposition of Tn does not generate deletions. Mol Gen Genet 1977, 154:205-211.

37. Norwouzian F, Hesselmar B, Saalman R, Strannegard I, Aberg N, Wold AE, Adlerberth I: Escherichia col in infants' intestinal microflora: colonization rate, strain turnover, and virulence gene carriage. Pediatr Res 2003, 54:8-14.

38. Smith CA, Thomas CM: Deletion mapping of $k i$ and $k$ o functions in the trf and $\operatorname{trf}$ regions of broad host range plasmid-RK2. Mol Gen Genet 1983, 190:245-254.

39. Chain PSG, Grafham DV, Fulton RS, FitzGerald MG, Hostetler J, Muzny D, Ali J, Birren B, Bruce DC, Buhay C, et al: Genome Project Standards in a New Era of Sequencing. Science 2009, 326:236-237.

doi:10.1186/1471-2180-12-53

Cite this article as: Humphrey et al:: Fitness of Escherichia coli strains carrying expressed and partially silent IncN and IncP1 plasmids. BMC Microbiology 2012 12:53. 